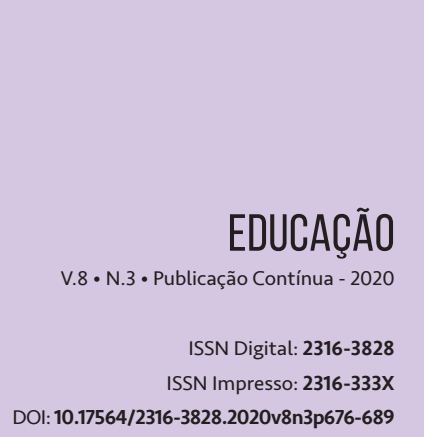

\section{POLÍTICAS EDUCACIONAIS E FORMAÇÃO DOCENTE NO ENSINO SUPERIOR}

\section{EUUCATIONAL POLICES AND TEACHER EDUCATION IN HIGHEREDUCATION}

Rachel Rachelley Matos Monteiro ${ }^{1}$ Maria de Lourdes da Silva Neta ${ }^{2}$ Antonio Germano Magalhães Junior ${ }^{3}$

\section{RESUMO}

A formação dos professores do ensino superior é necessária para a constituição da profissão docente, marcada pela mobilização dos saberes específicos da docência e que se entrelaçam sobre as políticas educacionais e institucionais. Dessa forma, este estudo objetivou compreender a formação dos professores do ensino superior em diálogo com a inserção das políticas educacionais, a partir de estudos bibliográficos e de documentais realizados em uma Instituição do Ensino Superior (IES). 0 percurso metodológico de abordagem qualitativa com técnicas de estudo bibliográfica e documental, fundamentamos nos estudos de Almeida (2012), Almeida e Pimenta (2014) e Rua (2012), dentre outros. Tivemos como resultado as discussões apresentadas por pesquisadores como contribuintes para a formação dos professores do ensino superior, a partir de políticas institucionais que mobilizem os conhecimentos da docência, assim, concluímos a necessidade de pensar uma política educacional no magistério superior que apresentem contribuições para a prática e profissão docente.

\section{PALAVRAS-CHAVE}

Formação dos Professores. Ensino Superior. Política Educacional. 


\section{ABSTRACT}

The education of higher education teachers is necessary for the constitution of the teaching profession, marked by the mobilization of the specific knowledge of teaching and which are intertwined with educational and institutional policies. Thus, this study aimed to understand the education of higher education teachers in dialogue with the insertion of educational policies, from bibliographic and documentary studies conducted in a Higher Education Institution-HEI. The methodological path of qualitative approach with bibliographic and documentary study techniques, we base on the studies of Almeida (2012), Almeida and Pimenta (2014) and Rua (2012), among others. We had as a result the discussions presented by researchers as contributors to the education of higher education teachers, from institutional policies that mobilize the knowledge of teaching, thus, we conclude the need to think of an educational policy in higher education that have contributions to the practice. and teaching profession.

\section{KEYWORDS}

Teacher Training. University Education. Educational Politics.

\section{RESUMEN}

La educación de los docentes de educación superior es necesaria para la constitución de la profesión docente, marcada por la movilización del conocimiento específico de la enseñanza y que se entrelazan con las políticas educativas e institucionales. Así, este estudio tuvo como objetivo comprender la educación de los docentes de Educación Superior en diálogo con la inserción de políticas educativas, a partir de estudios bibliográficos y documentales realizados en una Institución de Educación Superior-IES. El camino metodológico del enfoque cualitativo con técnicas de estudio bibliográfico y documental, nos basamos en los estudios de Almeida (2012), Almeida y Pimenta (2014) y Rua (2012), entre otros. Como resultado, tuvimos las discusiones presentadas por los investigadores como contribuyentes a la educación de los docentes de educación superior, a partir de políticas institucionales que movilizan el conocimiento de la enseñanza, concluyendo así la necesidad de pensar en una política educativa en la educación superior que contribuya a la práctica y profesión docente.

\section{PALABRAS-CLAVE}

Formación del profesorado. Enseñanza Superior. Política educativa. 


\section{INTRODUCÇÃO}

Nas últimas décadas são perceptíveis o aumento quantitativo e qualitativo nas pesquisas acerca da formação do professor, de modo específico dos que atuam na docência universitária, entendidas pelos pesquisadores como espaço de constituição de saberes específicos para o magistério e a da "professoralidade" 4 .

Desse modo, as políticas educacionais interligam-se a formação dos professores, e assim, são pensadas as políticas públicas, que geram os projetos, os planos que fomentam estratégias para a melhoria dos processos educativos. Desse modo, as políticas educacionais se organizam como possibilidades na discussão, reflexão e proposição que fomentem melhoras na formação de professores.

Este estudo emergiu a partir das discussões em um curso stricto sensu de um programa de Pós-Graduação em Educação do Estado do Ceará acerca das políticas educacionais e a formação de professores, em especial das mudanças significativas no processo de política públicas e a docência no ensino superior. Esse escrito justifica-se com a intencionalidade de revelar a relevância das políticas educacionais e a sua interferência na formação dos professores do ensino superior, bem como, as discussões do trabalho docente: o magistério. 0 debate sobre a temática também é oriundo a partir dos estudos sobre a formação de professores do ensino superior, os caminhos para a formação institucionalizada dos docentes universitários.

Temos como questionamento central a relação da formação dos professores e as transformações das políticas educacionais no contexto do ensino superior, especificamente na busca da formação para a docência. Objetivamos compreender a formação dos professores do ensino superior e o diálogo com a inserção das políticas educacionais. Com isso, a relevância deste estudo surge a partir das reflexões apresentadas na literatura existente para os caminhos de uma proposta formativa dos docentes do ensino superior, atrelada nas discussões de políticas educacionais. Possuindo como análise desse cenário uma Instituição de Ensino Superior (IES) do Estado do Ceará.

\section{MÉTODO}

O estudo de abordagem qualitativa que conforme Bogdan e Biklen (1994) na investigação qualitativa a fonte direta de dados é o ambiente natural, constituindo o investigador o instrumento principal, onde os pesquisadores interessam-se mais pelo processo do que simplesmente pelos resultados ou produtos.

Foi realizada a coleta e análise de dados por meio da pesquisa bibliográfica e documental. Segundo Gil (2002, p. 44), “[...] a pesquisa bibliográfica é desenvolvida com base em material já elaborado, constituído principalmente de livros e artigos científicos”, permitindo ao investigador abranger uma quantidade maior de fenômenos a partir do que já foi produzido sobre o tema pesquisado. Utilizando os documentos de uma IES do Estado do Ceará para entender o processo de desenvolvimento profissional e a inserção das políticas educacionais na Universidade.

4 Termo empregado no estudo de Ramirez (2019) que sinaliza sobre a busca de ser tornar professor, caminho esse vivenciado desde a formação inicial até a formação continuada. 
Analisamos o Projeto de Formação Docente 2011/2012 e o Plano de Desenvolvimento Profissional Docente - PDPD (2017). Este estudo respeita a conduta ética da pesquisa científica e utiliza de dados públicos para a discussão. Essa pesquisa articulou entre as discussões apresentadas na literatura e uma análise com a política institucional de uma IES.

Para tanto, dividimos este estudo nas seguintes seções: A docência universitária e os caminhos das políticas educacionais, que visa discutir a partir do campo da conceituação e dos documentos vigentes, com os estudos de Almeida (2012), Pimenta e Anastasiou (2014) e Rua (2012) em seguida o debate sobre a formação docente como componente da institucionalização das políticas educacionais evidenciados pelas análises dos documentos da IES e de estudos como de Hobold (2019) e Ramirez (2019).

\section{RESULTADOS E DISCUSSÃO}

\subsection{INIICIO DAS DISCUSSÕES: A DOCÊNCIA UNIVERSITÁRIA E OS CAMINHOS DAS POLITIICAS EDUCACIONAIS}

A formação de professores universitários surge em um contexto de discussões e reflexões sobre o processo de formação, caminhos vivenciados para a mobilização dos saberes docentes e práticas de ensino. Desse modo, a formação docente, contribuindo para a constituição da profissão que requer conhecimentos específicos sobre o ofício, em especial, aqui neste estudo da formação dos docentes do ensino superior.

Helene (2013) em sua obra "Um diagnóstico da Educação Brasileira” discorre as políticas educacionais e a construção da educação brasileira, apresentando as suas problemáticas e déficits nos últimos anos e enfatiza sobre a não efetivação das políticas educacionais. Quando discutimos a imersão de políticas docentes de formação de professores para o ensino superior, percebemos uma lacuna quando se refere a essa implementação, ainda mais, quando o assunto é sobre a formação dos docentes universitários.

No tocante a formação dos professores universitários a Lei de Diretrizes e Bases da Educação (LDB) n 9.394/96 no artigo 66, destaca que "A preparação para o exercício do magistério superior far-se-á em nível de pós-graduação, prioritariamente em programas de mestrado e doutorado” (BRASIL, 1996, p. 21).

Nesse sentido o professor universitário requer formações e titulações, em especial de uma formação lato sensu ou stricto sensu. A partir da indicação legal, é apresentado na literatura que os processos formativos dos docentes universitários se constituem em uma parcela dos casos nos cursos stricto sensu, é necessário refletirmos que essa formação tem como finalidade a pesquisa e não ao ensino, mesmo em programas de pós-graduação que possuem como cerne as discussões sobre "educação", "ensino" e "formação de professores”.

Assim, pensando sobre os caminhos das políticas educacionais para a formação do professor do ensino superior. Morosini (2000, p. 11) destaca ainda que

A docência universitária tem sido considerada uma caixa de segredos, na qual as políticas públicas omitiram determinações quanto ao processo do ensinar, ficando o mesmo afeto à instituição educacional, que por sua vez o pressupõe integrante da concepção de liberdade acadêmica docente 
Diante disso, as reflexões sobre a docência universitária são apresentadas como componente de discussão sobre aquisição da formação profissional e das políticas que tange a formação dos professores nesta etapa de ensino, dessa forma, necessário entendermos o conceito das políticas públicas percebida por Rua (2012, p. 16):

0 termo 'política', no inglês, politics, faz referência às atividades políticas: o uso de procedimentos diversos que expressam relações de poder (ou seja, visam a influenciar o comportamento das pessoas) e se destinam a alcançar ou produzir uma solução pacífica de conflitos relacionados a decisões públicas

Com isso, no intuito de alcançar ou produzir uma solução as políticas educacionais surgem na intencionalidade de contribuir para a organização do ensino, as discussões sobre a educação, suas formas e modalidades. Gatti, Barreto e André (2011, p. 31) destacam que:

Para melhor entender as políticas docentes é preciso considerá-las no bojo das políticas educacionais que as configuram. 0 caráter histórico das políticas educacionais remete, por sua vez, à necessidade de analisá-las com base no contexto nacional e internacional em que se inserem, às demandas de diferentes âmbitos a que procuram responder e à própria evolução das tradições educativas em que elas são desenhadas e postas em prática

Bem como a percepção de conhecimentos e saberes específicos do trabalho docente. Desse modo, a docência universitária entendida por Pimenta e Anastasiou (2014) a partir das discussões de cunho legal, apresenta a necessidade de as IES desenvolverem propostas formativas destinadas aos professores que atuam na instituição.

Com essa relação sobre "formar professores" caminham ao encontro das indagações que permeiam à docência universitária e as contribuições da busca de uma formação específica. Essa organização acentua-se nas propostas apresentadas pelas IES e dos documentos que buscam contribuir na formação e no trabalho docente dos professores do ensino superior.

Os estudos de Almeida (2012) nos aproximam dos desafios das políticas educacionais no ensino superior, destacando a existência da necessidade de formação para os docentes que atuam nesse nível de ensino, bem como a pertinência das políticas formativa docente nos âmbitos institucionais. Ressalta ainda que,

[...] sustentarmos que o ensino é atividade que requer conhecimentos específicos, consolidados por meio da formação pedagógica voltada especialmente para esse fim, e atualização constante das abordagens dos conteúdos e das novas maneiras didáticas de ensiná-los. (ALMEIDA, 2012, p. 71).

Assim, a necessidade de pensar a prática docente que contribua no processo de ensino-aprendizagem dos discentes. Ou seja, um conjunto de ações que pode caracterizar a docência do ensino superior pressupões elementos de várias concepções que se configuram no campo complexo da ação docente (ALMEIDA; PIMENTA, 2014). Dessa forma, discutir a docência universitária e a relação com 
as políticas educacionais é perceber que caminhos de cunho organizacional podem ser feitos para contribuir na formação e no trabalho dos professores.

Nesse sentido a Instituição de Ensino Superior pesquisada apresenta um cenário de discussões sobre o desenvolvimento profissional dos professores da sua instituição, contribuindo para a implementação das políticas institucionais que concerne a formação específica dos docentes universitários, aprovando o Projeto de Formação Docente (2011/2012, p. 6) com o eixo de concentração da Pedagogia Universitária que tem como objetivo:

Promover a formação dos docentes da [...] visando o desenvolvimento de atitudes, habilidades e a aquisição de conhecimentos relativos a uma pedagogia universitária, contribuindo para aprendizagens significativas dos discentes na perspectiva da sua profissionalização e cidadania.

Desse modo, atrelando a necessidade da "Pedagogia Universitária" como contribuinte na formação dos professores do ensino superior, posteriormente a essa ação foi criado o Plano de Desenvolvimento Profissional Docente da PDPD (2017) que tem como foco contribuir na capacitação profissional no magistério superior, assim, estabelecendo algumas metas como participações de eventos científicos na área da atuação profissional, cursos de formação específica na área pedagógica aos docentes em sua instituição e formações continuadas propostas pela própria IES. Estratégias como essa, contribui para a discussão do desenvolvimento profissional nas Instituições de Ensino Superior.

A “Pedagogia Universitária” é entendida por Almeida (2012, p. 96) como um “[...] conjunto de concepções de natureza pedagógica, psicológica, filosófica, política, ética e epistemológica que articulam a prática educativa e sustentam as conexões entre universidade e sociedade". Com isso, a necessidade das políticas educacionais que promovam a formação docente no ensino superior, vinculando teoria e a prática, mobilizando os saberes necessários para a reflexão sobre a sua ação como formadores de professores.

É necessário percebermos que ofício de ser professor é diferente das demais profissões, pois o docente tem como objeto de trabalho o próprio conhecimento e o ser humano. Dessa forma, o profissional de educação, que tem por objetivo ajudar no processo de aquisição do conhecimento e no processo cognitivo dos seus alunos. Com isso, é necessário percebermos as possibilidades inerentes ao ensinar que serão utilizadas para que esse processo aconteça numa dada realidade formativa. Segundo Imbernón (2010, p. 42)

A ideia central deve ser potencializar uma formação que seja capaz de estabelecer espaços de reflexão e participação, para que os professores aprendam com a reflexão e a análise das situações problemáticas dos cursos de formação de professores e para que partam das necessidades democráticas do coletivo, a fim de estabelecer um novo processo formador que possibilite o estudo da vida na sala de aula e nas instituições educacionais, os projetos de mudança e o trabalho colaborativo

Diante da ideia dos projetos de mudanças e do trabalho colaborativo, em especial, na busca de 
uma discussão sobre a formação pedagógica dos professores, e essa "formação pedagógica do ensino superior" é permeada em momentos de conflitos sobre a aquisição da formação específica da docência. Essa formação que precisa estar atrelada aos conhecimentos específicos da área como também a mobilização dos conhecimentos pedagógicos sobre o ensinar (PIMENTA; ANASTASIOU, 2014). Com isso a seguir apresentaremos as discussões evidenciadas na literatura e a discussão sobre a proposta institucional de políticas formativas ao magistério superior.

\subsection{A FORMAÇ̃̃O DOCENTE COMO COMPONENTE DA INSTITUCIONALIZAÇ̃̃O DE POLÍTICA EDUCACIONAL}

Nos estudos de Almeida (2012), Almeida e Pimenta (2014), Magalhães Junior e Cavaignac (2018), Mantovani e Canan (2015), Ramirez (2019) e Hobold (2018), todos apresentam em suas pesquisas desafios na formação de professores do ensino superior. E sinalizam a necessidade de as instituições de ensino pensarem em políticas institucionais para a busca de um desenvolvimento profissional que colabore com a formação docente nas IES.

Rua (2012), nos seus estudos ao apresentar o "ciclo de políticas" discute os principais modelos, permeando as agendas políticas, os atores e as análises de decisões políticas, como também entende o processo de implementação, avaliação e monitoramento das políticas, em especial a diferença entre eficiência, eficácia e efetividade. Desse modo, ao pensar uma política educacional é necessário pensar na sua estrutura organizacional como também na sua implementação e avaliação com as tomadas de decisões durante a execução.

Diante disso, Miranda e Magalhães Junior (2016, p. 36) entendem que

Toda política pública requer atenção aos condicionantes do processo que se constitui, como o valor político empregado, as condições de implementação (prática, ou seja, a viabilidade) e as condições políticas (de aceitabilidade) impregnadas, isto que os administradores públicos e os demais sujeitos operacionais destas políticas devem ter em vista suas contingências, entraves internos e externos, além das influências internacionais a que devem ignorar, ou dialogar, ou submeter-se.

Almeida (2012), pensando em políticas públicas, em destaque as institucionais, apresenta as experiências de formação e profissionalização de professores universitários em âmbito nacional e internacional. Assim, como os estudos mencionados nesta pesquisa todos os resultados apontam a necessidade da reflexão sobre o trabalho docente, o desenvolvimento profissional, a mobilização dos saberes docentes e da prática reflexiva e a busca de uma "Pedagogia Universitária”, dialogando com as ideias de Almeida (2012), Cavalcante (2014) sinalizou que:

Os docentes do ensino superior precisam se apropriar das contribuições da área pedagógica. Para isso, é necessário prover nas instituições de ensino superior a institucionalização de uma Pedagogia Universitária, tendo por referencial a pesquisa que ora se publica e as inúmeras indicações e possibilidades que aponta para que a prática pedagógica fertilize as práticas docentes, para que estas se tornem educativas. (CAVALCANTE, 2014, p. 16). 
O Plano de Desenvolvimento Profissional Docente da IES investigada apresentou um levantamento das disciplinas e cursos que podem ser ofertados ao corpo docente integrando-se ao plano de formação dos professores do ensino superior, principalmente realizando apontamentos por meio de estudos e participações em ciclos formativos acerca da formação pedagógica destes profissionais.

Com isso, apropriação das contribuições da área pedagógica sinalizam a necessidade da formação dos professores em um campo das políticas institucionais, sinalizado por Almeida e Pimenta (2014) como um lócus que requer atenção especial.

Nos estudos de Magalhães Junior e Cavaignac (2018, p. 915) ao mapear a docência universitária e a relação de saber/poder dos professores dos cursos de licenciatura de uma instituição de ensino superior, e evidenciar insuficiências na formação pedagógica dos professores, destacam que:

[...] a formação pedagógica dos professores precisa ser institucionalizada, pois não se pode conceber o desenvolvimento profissional somente como uma atitude individual do docente em busca de melhorias para sua prática. Quando o foco são professores universitários responsáveis pela formação de novos docentes, a preocupação aumenta. É necessário constituir uma cultura institucional que possibilite o desenvolvimento profissional docente, pois trata-se de um processo permanente e depende de políticas da instituição viabilizadoras de propostas formativas e de valorização da profissão docente.

Diante da acepção, constatamos que o desenvolvimento profissional docente é um dos aspectos preponderantes da formação continuada dos docentes do ensino superior. Assim, é percebido também na política da IES no Projeto de Formação Docente 2011-2012 ser pertinente que a discussão sobre o desenvolvimento profissional possa contribuir com as aprendizagens dos docentes e a profissionalização na referida instituição.

Desse modo, pensando a formação de professores como um conjunto de saberes e atribuições que precisam ser desenvolvidas em todo exercício profissional. Assim, Montovani e Canan (2015) destacam a pertinência das políticas de formação pedagógico-didáticas para a formação de professores do ensino superior, em especial, com o objetivo de melhorias na qualidade de ensino para a formação de novos profissionais e a formulação de novos questionamentos para a ciência, sinalizam também as legislações ao destinar ao magistério superior em âmbito das Instituições de Ensino Superior e os cursos de pós-graduação, mas que não organizam ou determinam um currículo mínimo para essa formação, principalmente, uma formação para a docência. No Projeto de Formação Docente (2011/2012, p. 6) é percebido também a necessidade de:

- Realizar cursos de formação pedagógicos iniciais e continuados, nas modalidades presenciais e a distância, tendo como eixo estruturante uma pedagogia universitária;

- Desenvolver grupos de discussão sobre a prática pedagógica do professor universitário, vinculando-os as ações do Programa;

- Realizar conferências, vídeos-conferência, grupos de estudo e de intercâmbio de experiências entre os professores, discutindo e dialogando sobre temáticas pedagógicas;

- Realizar ações de formação docente na perspectiva do ensino, pesquisa e extensão nas dimensões técnico-pedagógicas, científicas e estético culturais). 
Diante do exposto, percebe-se a necessidade do envolvimento dos profissionais na constituição dessa Pedagogia Universitária, como também, contribuindo dentro das ações desenvolvidas pelas políticas institucionais.

Ao delinear os estudos de Ramirez (2019) apresenta as Universidades como local de construção da socialização, dos conhecimentos científicos e da formação profissional. Contribui em descrever que os profissionais que estão em exercício da docência não se podem mais conceber que os domínios dos conteúdos sejam o único fator determinante para a docência, é necessário também saber ensinar. Aliando as competências técnicas dos conhecimentos (conteúdos) e a relação com as competências pedagógicas (ensino-aprendizagem, planejamento, avaliação e demais aspectos). Assim,

[...] é preciso refletir sobre o preparo efetivo do corpo docente, principalmente daqueles que nunca tiveram contato com uma formação pedagógica que propiciasse o desenvolvimento profissional, interligando competência técnica com competência pedagógica. (RAMIREZ, 2019, p. 43).

Na pesquisa desenvolvida por Hobold (2018) ao se debruçar sobre as investigações do desenvolvimento profissional dos professores, colaborando com os aspectos conceituais e práticos, como também modelos formativos da formação pedagógica dos professores, destacam 6 modelos:

1. Modelos de desenvolvimento profissional - aproximação com os processos formativos;

2. Modelo de desenvolvimento profissional autônomo;

3. Modelo de desenvolvimento profissional baseado nos processos de observação/supervisão e apoio profissional mútuo;

4. Modelo de desenvolvimento profissional no desenvolvimento curricular e/ou organizacional ou baseado em projetos;

5. Modelo de desenvolvimento profissional por meio de cursos de formação;

6. Modelo de desenvolvimento profissional por meio da investigação para a ação.

Todos esses aspectos configuram propostas vivenciadas por professores para a contribuição de uma aproximação de formação pedagógica e de política de institucionalização docente.

No Modelo 1, ancorados em estudos de Oliveira-Formosinho (2009) a autora Hobold (2018) apresenta o contexto do desenvolvimento profissional docente que perpassa toda a formação contínua. Desde, as suas vivências em processo de formação inicial, no exercício do magistério, sendo na educação básica ou no ensino superior e a relação das crenças estabelecidas anterior a estes processos, ou seja, compreende a trajetória de cada sujeito como preponderante neste modelo formativo, mas existe a necessidade de uma formação em processo que contribua nessa constituição docente, diferentemente do que acontece no Modelo 2 com o "desenvolvimento autônomo" que apresenta as concepções que os professores aprendem sozinhos por meios de leituras, pesquisas. Estudos e entre outros aspectos.

No Modelo 3 intitulado "Modelo de desenvolvimento profissional baseado nos processos de observação/supervisão e apoio profissional mútuo" destaca a observação de outros profissionais de educação na prática exercida pelo professor, ou seja, um modelo formativo que os professores obser- 
vem e contribuam para a prática profissional, e, assim, para a formação e o desenvolvimento profissional. Para esse modelo Hobold (2018, p. 435) destaca que:

O que importa, nesse modelo de formação, é que um dos profissionais que observa e/ou assista à prática do docente tenha um preparo para dar um retorno ao professor sobre o desenvolvimento de uma aula ou a explicação/o trabalho com um determinado conteúdo, organização e condução das atividades, o manejo da disciplina e referente ao aspecto relacional com os estudantes

No Modelo 4 é proposta uma atividade realizada a partir de uma sugestão idealizada pelo corpo docente, sendo desenvolvida em uma estrutura de projeto e que visa contribuir o desenvolvimento profissional dos professores, esse modelo se adequa, principalmente, em uma instituição de ensino específico. 0 modelo 5 que se constitui a partir de cursos de formação tem como foco oportunizar espaços de formação formal para os professores, sendo realizados por meios de oficinas, conferências, conteúdos, trabalhos em grupos e entre demais atividades, o que sinaliza nesse modelo é a participação dos próprios professores no processo formativo, onde essas atividades são propostas pelos próprios sujeitos dentro do processo, destaca ainda mais que os formadores são os sujeitos e colegas de profissão.

No Mmodelo 6 de desenvolvimento profissional por meio de investigação para a ação, constitui como uma parceria de pesquisa entre o campo da educação básica e do ensino superior, principalmente, percebendo a educação básica como um espaço de pesquisa e de própria formação, destaca ainda que "[...] fica evidente certa autonomia imputada aos professores pelo seu processo de desenvolvimento profissional, no sentido de que busquem respostas, por meio de investigações, a situações do cotidiano educacional” (HOBOLD, 2018, p. 440). Necessário nos atentar para o Modelo 6 que a troca de saberes e experiências precisam coexistir para ambos os lados e não apena um ambiente de coleta de dados que não oportuniza uma experiência de desenvolvimento profissional.

Todos esses modelos, são caminhos e possibilidades de pensarmos em políticas educacionais para a docência, principalmente, contribuindo para o magistério no ensino superior. Com isso, é recomendável que as discussões sobre as políticas educacionais sobre a formação do professor do ensino superior, esteja dialogando com as necessidades do Estado como também das instituições de ensino com a institucionalização ou até mesmo propostas de formativas que contribua para a busca do "saber ensinar" dos seus profissionais da educação.

Diante disso, por meio de uma análise das pesquisas apresentadas em diferentes instituições do ensino superior pelo Brasil, percebe-se semelhanças nos resultados das pesquisas de que precisamos efetivamente de políticas educacionais que contribuam para a formação pedagógica dos professores. E que as IES atentem para a implementação de políticas que respeitem as características da instituição, mapeando as necessidades de formação, constatando as dificuldades vivenciadas na gestão de sala de aula, subsidiando as propostas formativas.

Desse modo a IES pesquisada, caminha para as discussões sobre o desenvolvimento profissional docente e a busca de uma formação continuada para os seus profissionais, é necessário entendermos que as metas estabelecidas e as propostas vivenciadas pela instituição contribuem 
para esse processo contínuo de “constituir-se" professor, mas que é preciso uma participação e mobilização dos próprios docentes em sua participação no processo formativo. Com isso, é necessário que o professor do ensino superior mobilize os conhecimentos acerca dos conteúdos e dos saberes da prática pedagógica.

\section{CONCLUSÃO}

Este trabalho teve como intuito compreender a formação dos professores do ensino superior e seu diálogo com as políticas educacionais, realizando uma análise da implementação de ações formativas de uma Instituição do Ensino Superior pública. Desse modo, o objetivo deste estudo foi concretizado ao constatarmos a partir da literatura a necessidade de formação dos professores e os (des)caminhos das políticas educacionais, ainda mais, evidenciados a partir da discussão de uma formação pedagógica para o exercício da profissão docente nesse nível de ensino.

A inserção das políticas educacionais e institucionais surgem como possibilidades de contribuir para a formação dos docentes universitários. Mas que em aspectos legais e de políticas públicas ao docente do ensino superior, apresenta-se ainda uma fragilidade em diretrizes e regulamentação nacional desses profissionais nessa etapa de ensino.

Porém, já é evidenciado na literatura, como apresentado neste artigo, contribuições para pensar em políticas para a formação do professor, aproximando os conteúdos específicos com os saberes da docência, contribuindo assim, para o ensino e a expansão educacional em território nacional. Como também já são encontrados ações, projetos e programas que compõem as políticas institucionais de algumas IES.

Concluímos que a discussão que se insere à docência universitária é um campo que precisa de diálogo, de investigação acerca de diversos aspectos, principalmente sobre a legitimidade de uma formação continuada que atrele a mobilização dos saberes específicos para o ofício docente. Como também nos faz refletir em que caminhos educacionais a formação de professores do ensino superior se insere em um campo de possibilidades acerca do "fazer-se docente". E que nós professores e pesquisadores podemos contribuir para a busca de uma docência em que os componentes de uma prática docente refletida estejam em consonância. Ainda mais ao pensar em que caminhos podemos trilhar para a busca de uma profissão docente.

\section{REFERÊNCIAS}

ALMEIDA, Maria Isabel de. Formação do professor do ensino superior: desafios e políticas institucionais. São Paulo: Cortez, 2012.

ALMEIDA, Maria Isabel de; PIMENTA, Selma Garrido. Pedagogia universitária - Valorizando o ensino e a docência na universidade. Revista Portuguesa de Educação, CIEd - Universidade do Minho, v. 
27, n. 2, p. 7-31, ( ) 2014. Disponível em: http://www.scielo.mec.pt/scielo.php?script=sci_arttext๕pi $\mathrm{d}=$ S0871-91872014000200002. Acesso em: 6 ago. 2019

BRASIL. Ministério da Educação. Lei no 9.394, de 20 de dezembro de 1996. Estabelece as diretrizes e bases da educação nacional. 13. ed. Brasília: Câmara dos Deputados, 2016. 25 p.

CAVALCANTE, Maria Marina Dias. Pedagogia universitária: um campo de conhecimento em construção. Fortaleza: EdUECE, 2014.

GATTI, Bernadete Angelina; BARRETO, Elba Siqueira de Sá; André, Marli Eliza Dalmazo de Afonso.

Políticas docentes no Brasil: um estado da arte. Brasília: UNESCO, 2011.

GIL, Antonio Carlos. Como elaborar projetos de pesquisa. São Paulo: Atlas, 2002.

HOBOLD, Márcia de Souza. Desenvolvimento profissional dos professores: aspectos conceituais e práticos. Práxis Educativa, Ponta Grossa, v. 13, n. 2, p. 425-442, maio/ago. 2018. DOI: 10.5212/ PraxEduc.v.13i2.0010. Disponível em: https://www.revistas2.uepg.br/index.php/praxiseducativa/ article/view/10336. Acesso em: 20 nov. 2019.

IMBERNÓN, Francisco. Formação continuada de professores. Porto Alegre: Artmed, 2010.

MAGALHÃES JÚNIOR, Antonio Germano; CAVAIGNAC, Mônica Duarte. Formação de professores: limites e desafios na educação Superior. Cadernos de pesquisa, v. 48, n. 169, p. 902-920, jul./set. 2018. DOI: 10.1590/198053145405. Disponível em: http://www.scielo.br/scielo.php?script=sci_ abstract\&pid=S0100-15742018000300902\&lng=en\&nrm=iso\&tlng=pt. Acesso em: 20 nov. 2019.

MIRANDA, Augusto Ridson de Araújo; MAGALHÃES JUNIOR, Antonio Germano Magalhães. Política educacional, formação de professores e profissão docente: um olhar sobre a formação docente em história na UECE. Jornal de Políticas Educacionais, v. 10, n.19, p. 34-44, jan./jun. 2016. Disponível em: https://revistas.ufpr.br/jpe/article/view/49954/30036. Acesso em: 20 nov. 2019.

OLIVEIRA-FORMOSINHO, Julia. Desenvolvimento profissional dos professores. In: FORMOSINHO, J. (coord.). Formação de professores: aprendizagem profissional e acção docente. Portugal: Porto Editora, 2009. p. 221-284.

PIMENTA, Selma Garrido; ANASTASIOU, Léa das Graças Camargos. Docência no ensino superior. 5. ed. São Paulo: Cortez, 2014. 
RAMIREZ, Vera Lucia. A docência na educação superior e a constituição da professoralidade. Revista Educação, Porto Alegre, v. 41, n. 1, p. 41-48, jan./abr. 2018. Disponível em: http://revistaseletronicas. pucrs.br/ojs/index.php/faced/article/view/29600/16845. Acesso em: 6 ago. 2019.

RUA, Maria das Graças. Políticas públicas. Florianópolis: Departamento de Ciências da Administração/UFSC; [Brasília]: CAPES: UAB, 2012. 
1 Graduação em Pedagogia pela Universidade Estadual do Ceará (UECE). Mestranda em Educação pelo Programa de Pós-Graduação em Educação da Universidade Estadual do Ceará (PPGE/UECE). Bolsista na pós-graduação da Fundação Cearense de Apoio ao Desenvolvimento Científico e Tecnológico (FUNCAP).

2 Graduação em Pedagogia e Administração pela Universidade Estadual do Ceará (UECE). Especialista em Administração Escolar e Gestão de Recursos Humanos e Planejamento, Implementação e Gestão de Cursos a Distância (UFF). Mestrado e doutorado em Educação pelo Programa de Pós-Graduação em Educação da Universidade Estadual do Ceará (PPGE/UECE).

3 Graduação em Pedagogia pela Universidade Federal do Ceará (UFC), graduação em História pela Universidade Estadual do Ceará (UECE), especialização em pesquisa educacional pela Universidade Federal do Ceará (UFC) e educação a distância pela Universidade de Brasília (UnB), mestrado e doutorado em Educação pela Universidade Federal do Ceará (UFC) e pós-doutorado em Educação pela Universidade Federal do Rio Grande do Norte (UFRN).

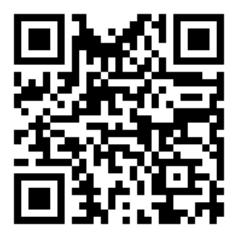

A autenticidade desse artigo pode ser conferida no site https://periodicos. set.edu.br

\section{(ㄷ) (1) (-)}

Este artigo é licenciado na modalidade acesso abertosob a Atribuição-Compartilhalgual CC BY-SA

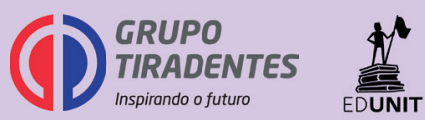

